\title{
Quantifying wave exposure in shallow temperate reef systems: applicability of fetch models for predicting algal biodiversity
}

\author{
Nicole A. Hill' ${ }^{1, *}$, Austen R. Pepper ${ }^{1,4}$, Marji L. Puotinen ${ }^{2,5}$, Michael G. Hughes ${ }^{3,6}$, \\ Graham J. Edgar ${ }^{1}$, Neville S. Barrett ${ }^{1}$, Rick D. Stuart-Smith ${ }^{1}$, Rebecca Leaper ${ }^{1}$ \\ ${ }^{1}$ Tasmanian Aquaculture and Fisheries Institute, University of Tasmania, Private Bag 49, Hobart, Tasmania 7001, Australia \\ ${ }^{2}$ Institute for Conservation Biology and Environmental Management and School of Earth and Environmental Sciences, \\ University of Wollongong, Wollongong, New South Wales 2522, Australia \\ ${ }^{3}$ Marine \& Coastal Environment Group, Geoscience Australia, GPO Box 378, Canberra ACT 2601, Australia \\ ${ }^{4}$ Present address: New South Wales State Emergency Service, Level 3, 6 - 8 Regent Street, Wollongong, \\ New South Wales 2500, Australia \\ ${ }^{5}$ Present address: School of Earth Sciences, The Ohio State University, 125 South Oval Mall, Columbus, Ohio 43210, USA \\ ${ }^{6}$ Present address: School of Geosciences, University of Sydney, Sydney, New South Wales 2006, Australia
}

\begin{abstract}
Management and conservation of ecosystems relies on biodiversity data; however broad-scale biological data are often limited. Predictive modelling using environmental variables has recently proven a valuable tool in addressing this gap. Wave exposure is a particularly important environmental variable that structures shallow reef systems, but it is rarely quantified across the large areas often used for predictive studies. Therefore, we investigated approaches that quantify exposure and can be readily applied across a large area. We generated 6 quantitative indices that emphasise different aspects of exposure using a numerical wave model and cartographic fetch models. The utility of these indices for predictive modelling in shallow temperate reef systems was assessed by how well they explained community and genera-level algal patterns in Tasmania, Australia, which is a region that experiences a wide range of wave exposure conditions. Exposure indices were significant predictors of algal patterns, explaining up to $18 \%$ of community level patterns and up to $37 \%$ of the variance associated with the occurrence and cover of algal genera. Fetch-based indices in particular appear to be a viable option for quantifying exposure on shallow reefs. These indices can be generated within a Geographic Information System (GIS) program for specific sites of interest, along coastlines or on a grid, and are potentially accessible to ecologists. Quantification of exposure across broad regions using fetch indices will allow ecologists to makes advances in predictive modelling studies, but also facilitate studies that test the generality of hypotheses and mechanisms driving patterns previously observed using qualitative measures
\end{abstract}

KEY WORDS: Wave exposure index $\cdot$ Cartographic fetch modelling $\cdot$ Macro-algae $\cdot$ Biodiversity Predictive models

Resale or republication not permitted without written consent of the publisher

\section{INTRODUCTION}

Understanding and predicting patterns of biodiversity is increasingly important for the conservation and management of ecosystems world-wide (Reid 1998, Austin 2002, Guisan et al. 2006). In the marine environ- ment, shallow reefs support diverse ecosystems that are currently under threat from the effects of fishing (Jackson et al. 2001), pollutants (Johnston \& Roberts 2009), introduced species (Walker 1998) and climate change (Hoegh-Guldberg et al. 2007). Prioritising areas for effective protection and long-term conserva- 
tion of shallow reef communities requires knowledge of biodiversity patterns across large regions. Because collecting biological data is labour intensive, difficult and expensive for the large areas relevant to management, these data are often limited and patchy. Where biological data are limited or lacking, predicting patterns of biodiversity using relationships between biodiversity and physical variables can facilitate conservation decision-making (Lehmann et al. 2002, Beger \& Possingham 2008, Foster \& Dunstan 2010).

A range of physical data is now available across large regions to aid in the development of predictive models for the marine environment. These include data on sea surface temperature or ocean colour from satellites (e.g. MODIS and SeaWiFS) or Argo floats, ocean chemistry measurements (e.g. CSIRO Atlas of Regional Seas, CARS; Condie \& Dunn 2006), bathymetry (e.g. Whiteway 2009) and sediment grain-size data (e.g. Marine Sediment database, MARS; Geoscience Australia). While these physical data have proven useful for ecosystems such as the continental shelf and slope (Foster \& Dunstan 2010), the suitability of some datasets for shallow, coastal environments is questionable. This is due to a range of issues that include reduced coverage inshore, uncertainty created by interpolation from offshore data (Condie \& Dunn 2006), and artefacts that affect satellite data, such as turbidity and tannin levels in coastal waters (Zibordi 2009). Thus, identifying and developing a suite of physical measures that are likely to be important drivers of shallow reef community structure is necessary for the success of predictive models of these ecosystems.

Exposure is a physical measure that has long been recognised by ecologists as an important factor in structuring reef communities. It includes forces such as waves generated by local winds, waves generated by remote weather systems (swell) as well as tides and currents. The water movement associated with exposure can have both positive and negative effects on shallow reef organisms as it supplies nutrients and particles to benthic organisms (Hurd 2000), disperses propagules (e.g. Hunt \& Scheibling 1996), can affect light availability (e.g. Carruthers et al. 2002), influences sedimentation and scouring processes (e.g. Airoldi \& Cinelli 1997), and can act as a physical disturbance removing organisms from the substratum (Vadas et al. 1990, Thomson et al. 2004). In shallow temperate reef systems, macro-algae often dominate the community and are directly affected by exposure, which can influence algal morphology (Wernberg \& Thomsen 2005, D'Amours \& Scheibling 2007), the distribution of species (Kennelly 1989, Fowler-Walker et al. 2005), and hence the composition and diversity of communities (Collings \& Cheshire 1998, England et al.
2008). However, exposure is often only qualitatively described and subjectively categorised, hindering generalisation of results across studies and geographic regions (Lindegarth \& Gamfeldt 2005). Thus, the development of standardised, quantitative measures of exposure, generated at broad scales and applicable to a range of shallow-water systems is timely.

Currently, quantifying wave exposure over regions generally is either by (1) numerical wave modelling or (2) cartographic fetch modelling. Deep-water wave models (such as WAM; WAMDI Group 1988) model offshore wave climatology. They are available at continental scales (or greater), but generally have a coarse grain and do not model shallow-water processes such as shoaling, refraction, diffraction or breaking (Hughes \& Heap 2010). Shallow-water models such as Simulating Waves Nearshore (SWAN; Booij et al. 1999) do and therefore, can model detailed variation in exposure due to complex bathymetry and coastline. Generally however, these high resolution models have only been run over small areas which has limited their utility for broad-scale studies (England et al. 2008). Few studies have generated or used wave models in ecological modelling (see England et al. 2008). This is because they are complex models to run that are typically calibrated using field data and expert knowledge, are computationally intensive, and in many cases are not easily generated or sourced by ecologists.

An alternative approach to quantifying wave exposure is to use a cartographic fetch model within a Geographical Information System (GIS). These models are based on fetch, i.e. the distance of water over which wind can blow uninterrupted in a given direction from the point of interest (or practically speaking, the distance to the nearest wave-blocking obstacle in a given direction). Fetch, along with the magnitude and duration of wind, limits the magnitude of the waves that can form in a given location (Denny 1988). Thus, measuring fetch alone provides an estimate of local sea-state and hence wave exposure at a given location. Fetch models can range from simple measures, such as the average fetch along a number of fetch lines, to methods that incorporate local wind speed and directional data and/or the effects of bathymetry (e.g. Malhotra \& Fonseca 2007). Fetch modelling can be easily implemented in a GIS program, does not require calibration, and is less computer intensive than numerical wave modelling. As fetch models are designed to estimate local conditions, they do not specifically model waves due to swell that may originate from offshore systems. They also do not account for nearshore processes such as the refraction, diffraction and breaking of waves.

Despite these limitations, fetch models have been successfully applied within an ecological modelling 
context to describe and predict relationships between exposure and rocky shore communities (Burrows et al. 2008), seagrass beds (Fonseca \& Bell 1998), algal occurrence (Ruuskanen et al. 1999) and algal morphology (Bekkby et al. 2009). As may be expected, most fetch-based studies have been conducted in semienclosed waters (where locally-generated wind waves dominate) on local to regional scales (but see Burrows et al. 2008). Shallow-reef ecosystems dominate open coasts, especially in Australia, and there is a need to develop a general exposure measure that can be applied to semi-enclosed and open coastal shallow reefs across broad regions.

In this paper we generated a series of quantitative exposure indices with the aim of identifying a useful index for shallow reef systems over large coastal areas. The first set of indices was generated using outputs from a deep-water model to test whether a currently available, broad-scale, wave climate model is able to explain patterns of biodiversity. The second set of indices was derived from fetch models and represent a finer-scale approximation of exposure. The third type of index is a composite index that combines the strengths of both a wave climate model and a fetch model. We then assessed the performance of the exposure indices in explaining patterns in algal biodiversity in Tasmania, Australia which is a temperate region that experiences a wide range of wave exposure conditions, at both semi-enclosed and open coastal sites.

\section{METHODS}

Study region and ecological data. The coastline of Tasmania in southern Australia spans nearly 3000 km, experiences a wide range of exposure conditions, and supports a range of diverse algal communities (Bolton 1994). The western and southern coasts of Tasmania are subject to frequent and intense weather systems originating in the Southern Ocean and moving eastwards, generating gale force winds and large swell waves (Porter-Smith et al. 2004). The north coast to some extent is buffered by the Bass Strait, a relatively shallow body of water ( $\sim 0$ to $100 \mathrm{~m}$ water depth) that dampens the effects of oceanic swell and separates Tasmania from mainland Australia. On occasion, however, the north coast is subject to storm surges, wind waves and tidal currents (Porter-Smith et al. 2004). The east coast of Tasmania experiences variable and less predictable oceanic conditions (Hemer et al. 2008).

Algal data were collected in Tasmania as part of a long-term shallow temperate reef monitoring program (Barrett et al. 2009, Stuart-Smith et al. 2010) established in 1992 using underwater visual censuses
(UVC). Each census consisted of a diver-based survey along a $200 \mathrm{~m}$ transect of reef at a site. The data used here were limited to surveys conducted on mainland Tasmania in 2006-2007 at sites of $5 \mathrm{~m}$ water depth, and represented a mixture of semi-enclosed and open coastal sites. The national marine bioregionalisation scheme's (IMCRA 4.0, Commonwealth of Australia 2006) meso-scale bioregions for Tasmania broadly align with the regions of differing exposure regimes described above. These bioregions were used as a means to subset the data and attain a representative coverage of sites across the exposure gradient. A total of 79 sites were used in the analysis (Fig. 1) with 17 to 21 sites chosen from each of 4 of the 5 bioregions. The fifth bioregion (Franklin) was not included in this study because there were too few survey sites available for analyses due to the remoteness of the region.

Algal cover along each transect was recorded using $0.5 \times 0.5 \mathrm{~m}$ quadrats with 50 points per quadrat (Barrett et al. 2009). Twenty quadrats were censused per transect. The cover of canopy species was recorded first and then pushed aside and the points falling on understorey species were counted. Algae were identified to

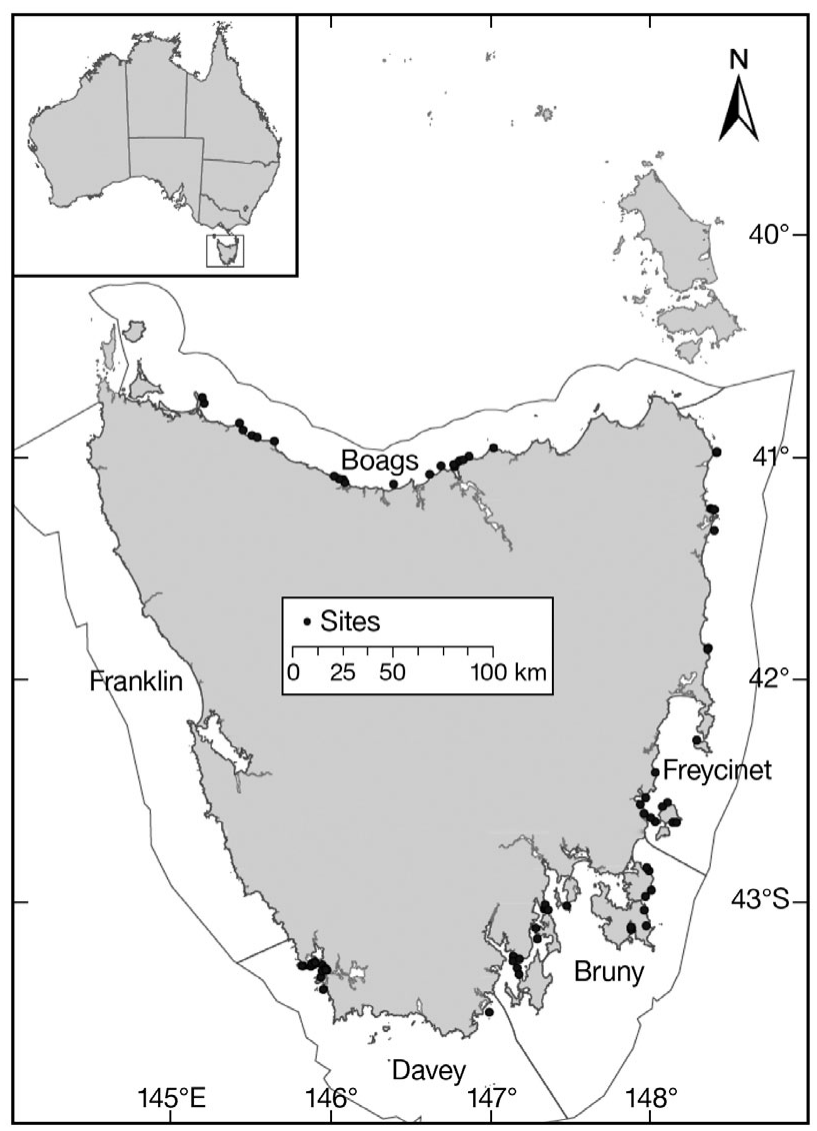

Fig. 1. Tasmania. Meso-scale bioregions and the locations of sites surveyed for algae 
the lowest possible taxonomic level in situ, usually species, otherwise to genus and in some cases to broader functional groups (e.g. encrusting coralline algae). The percent cover of each algal species was calculated at the level of site and aggregated to genera as the lowest taxonomic level for analysis.

Calculation of exposure indices. Three classes of exposure indices were generated: (1) derived from the numerical model for deepwater waves, (2) derived from fetch models, and (3) one that combines outputs from the offshore wave model with outputs from a fetch model. These are described below and in Table 1.

Offshore wave model indices were based on outputs from the AusWAM model; they represent exposure in the context of offshore wave climatology. AusWAM is an extension of the WAM model (WAMDI Group 1988), a third generation wave model that incorporates local winds, energy attenuation due to bottom friction, and swell propagation, but does not specifically model processes that may occur in very shallow waters near to the shoreline $\left(<25 \mathrm{~m}_{i}\right.$ Hughes \& Heap 2010). AusWAM is available for the entire Australian region at a 0.1 degree resolution (approximately $11 \times 8 \mathrm{~km}$ at $42^{\circ} \mathrm{S}$ ) and is routinely run by the Australian Bureau of Meteorology for forecasting ocean conditions (Greensdale 2001). AusWAM produces 6-hourly predictions of significant wave height, wave period and wave direction. Here, we used a hindcast dataset spanning $11 \mathrm{yr}$ from 1997 to 2008 and extracted the time-averaged model values (Hughes \& Heap 2010). For the indices (below) extracted from AusWAM, sites were assigned the closest model data point using nearest neighbour methods in the GIS.

(A) 'Mean_Hs' is the mean significant wave height over the 11-yr hindcast AusWAM dataset and represents average broad-scale wave conditions.
(B) '90th percentile_Hs' is the 90th percentile of significant wave height over the AusWAM dataset and represents extreme broad-scale wave conditions.

Fetch-based indices were generated using the recently developed Generic Relative Wave Exposure Model (GREMO, Pepper 2009, Pepper \& Puotinen 2009) implemented within the ArcMap ${ }^{\mathrm{TM}}$ program in ArcGIS ${ }^{\text {TM }} 9.3$ (ESRI product). GREMO provides a number of options for calculating relative exposure indices based on generalised versions of fetch models previously published in the literature (Ekebom et al. 2003, Puotinen 2005, Malhotra \& Fonseca 2007, Burrows et al. 2008), and can incorporate wind and bathymetric data (Pepper \& Puotinen 2009). The minimum requirement to run GREMO is a dataset representing the location of wave-blocking obstacles (i.e. coastline and islands) and the location of the points for which the relative exposure index is to be calculated. Here, for the former, we used a 1:100 000 scale coastline as it represented the highest resolution digital map available for the entire coastline of Australia (GEODATA Coast 100K 2004, Geoscience Australia). For the latter, spatial co-ordinates for survey sites were recorded using GPS in the field. Three fetch-based indices were calculated:

(a) 'Openness' is a measure of the distance of a site to the nearest coastline in all directions and assumes that locally-generated seas (and/or swell) are equally likely to approach a site from any direction. Fetch lines were constructed around a site at $7.5^{\circ}$ spacing to a maximum distance of $650 \mathrm{~km}$. This distance represents the fetch length required for seas to become fully developed (i.e. maximal wave conditions) under gale force wind conditions (based on equations in Denny 1988 and gale force winds defined by the Bureau of Meteorology as $17.49 \mathrm{~m} \mathrm{~s}^{-1}$ ). Openness was calculated as the sum of the length of the 48 fetch lines constructed per site and

Table 1. Exposure indices used in this study, their description, derivation and interpretation

\begin{tabular}{|c|c|c|c|c|c|}
\hline Index & Abbreviation & Type & Units & Calculation & Interpretation \\
\hline Openness & Open & GIS & Dimensionless & $\begin{array}{l}\text { Average of fetch in } 48 \text { directions to a } \\
\text { maximum of } 650 \mathrm{~km}\end{array}$ & $\begin{array}{l}\text { Potential exposure to locally generated } \\
\text { seas and undefined swell }\end{array}$ \\
\hline Wind fetch & Wind & GIS & Dimensionless & $\begin{array}{l}\text { Fetch weighted by proportion of time } \\
\text { wind blows in each direction }\end{array}$ & Locally generated wind wave exposure \\
\hline $\begin{array}{l}\text { Bathymetry- } \\
\text { altered fetch }\end{array}$ & Bathy & GIS & Dimensionless & Fetch weighted by bathymetric layer & $\begin{array}{l}\text { Potential exposure accounting for some } \\
\text { effects of seafloor slope }\end{array}$ \\
\hline Mean_Hs & Mean_Hs & $\begin{array}{l}\text { Wave } \\
\text { model }\end{array}$ & $\mathrm{m}$ & $\begin{array}{l}\text { Mean significant wave height } \\
\text { extracted from hindcast AusWAM } \\
\text { model (Geoscience Australia) }\end{array}$ & Broad-scale mean wave climate \\
\hline $\begin{array}{l}\text { 90th } \\
\text { percentile_Hs }\end{array}$ & 90_Hs & $\begin{array}{l}\text { Wave } \\
\text { model }\end{array}$ & $\mathrm{m}$ & $\begin{array}{l}\text { 90th percentile significant waveheight } \\
\text { extracted from hindcast AusWAM } \\
\text { model (Geoscience Australia) }\end{array}$ & Broad-scale extreme wave climate \\
\hline $\begin{array}{l}\text { Potential wave } \\
\text { climate }\end{array}$ & $\begin{array}{l}\text { PWC } \\
\quad \text { we }\end{array}$ & $\begin{array}{l}\text { Wave } \\
\text { model } \\
\text { ighted GIS }\end{array}$ & Dimensionless & $\begin{array}{l}\text { Fetch weighted by directional } \\
\text { Mean_Hs values }\end{array}$ & $\begin{array}{l}\text { Potential exposure taking into account } \\
\text { the direction of the mean wave climate }\end{array}$ \\
\hline
\end{tabular}


was subsequently normalised by dividing by the maximum possible sum of fetch lengths. Indices were normalised to provide a standardised index that allows comparison with future indices generated by GREMO that may use different model settings.

(b) The 'wind fetch' index incorporates information on local wind conditions and therefore represents exposure in terms of local wind waves. Wind information was sourced from the Australian Government's Bureau of Meteorology (www.bom.gov.au) for all stations within $20 \mathrm{~km}$ of the coast and for the period between 1990 and 2008. Sites were assigned data from the closest suitable weather station using nearest neighbour methods in the GIS. These were then visually checked to ensure that the most appropriate weather station had been chosen and manually re-assigned where necessary. For example, a site on the lee side of an island or peninsula that was assigned to a weather station located on the exposed coast was re-assigned to one more representative. Directional wind records from each weather station were then processed to give the proportion of time wind blew from 16 sectors of the compass. Following Malhotra \& Fonseca (2007), each fetch line generated for a site using the openness index was weighted by the proportion of time wind blew in that sector (Pepper 2009). Again, fetch lines were summed and then normalised at each site to create the wind fetch index.

(c) 'Bathymetry-altered fetch' attempts to account for the attenuation of wave energy as waves move into shallow waters and encounter friction with the seafloor. A bathymetry raster dataset was created for input into the GREMO program based on the Australian Bathymetry and Topography Grid (Whiteway 2009) and supplemented with nearshore data collected by the SEAMAP Tasmania project (Tasmanian Aquaculture and Fisheries Institute, www.utas.edu.au/tafi/ seamap). The cell size of this raster dataset was set to $250 \mathrm{~m}$ and SEAMAP data was aggregated up to this resolution. Accordingly, bathymetry was sampled every $125 \mathrm{~m}$ along each fetch line. The fetch lines were altered using an algorithm modified from Malhotra \& Fonseca (2007) (see the supplement for details, available at www.int-res.com/articles/suppl/m417p083_ supp.pdf) with a distance decay value of 0.5 (Pepper 2009). Each fetch line is split into segments which are individually shortened in proportion to the shallowness of the water depth along them, and then summed to generate a new overall fetch line. The algorithm uses an inverse distance weighting (IDW), which weights the bathymetric context closer to a site as more influential than that further away (Pepper \& Puotinen 2009). The overall effect of the algorithm is to shorten fetch lines (and hence lower the exposure value) according to bathymetric conditions across the study area (Fig. S1 in the supplement). Missing depth values (i.e. located very close to the coast) were set to a value of $1 \mathrm{~m}$. Values of individual fetch lines for a survey site were summed and then normalised to produce the bathymetry-altered fetch index.

Index combining wave and fetch models. Fetchbased exposure indices are useful in accounting for potential exposure to locally generated waves, but do not specifically incorporate any information on the occurrence and magnitude of swell likely to affect the region. Conversely, the wave model used here to describe the offshore wave climate is generated on a much broader scale than survey sites and does not incorporate localised information that can affect exposure. In an attempt to incorporate as much localised site information as possible but to also account for regional differences in wave climate, a third type of index that combines fetch-based and offshore wave model information was generated. The 'potential wave climate' index estimates the potential wave climate reaching a site by weighting the fetch lines generated in the openness index by the directional spectra of mean significant wave height extracted from the AusWAM model.

Statistical analyses. We used multivariate techniques to examine patterns in algal community composition with respect to exposure. We tested the performance of each exposure index in explaining patterns in the algal community data with distance-based linear models using DISTLM available in the PERMANOVA+ package in PRIMER (PRIMER-E, Plymouth). The method is based on distance based redundancy analysis (dbRDA, McArdle \& Anderson 2001) and models the linear relationship between one or more predictor variables and the multivariate data as described by a resemblance matrix (Anderson et al. 2008). Model hypotheses are tested using p-values generated by permutation methods.

DISTLM was performed on a Bray-Curtis dissimilarity matrix generated from the algal cover data. Data were square root transformed to increase the contribution of less common genera to the analyses. To account for a potential non-linear relationship between predictor variables and algal community composition, quadratic (as well as linear) terms were tested for each index. The proportion of community level variance explained by an index in marginal tests was used as a measure of performance.

Occurrence data are the simplest measure of a species' distribution and are commonly modelled in predictive studies (e.g. Beger \& Possingham 2008, Williams et al. 2009). The ability of each exposure index to explain the presence or absence of 10 common algal genera was tested using generalised linear models (GLMs), specifically a binomial GLM with a logit link function. For each index, 2 models were initially tested: 
a model with only the linear term and a model with linear and quadratic terms. Quadratic terms were considered to account for the likelihood that algal genera occupy a niche along an exposure gradient (Austen 1985). The most parsimonious model for each index was chosen using Akaike's Information Criteria (AIC) with lower values indicating a 'better' model (Burnham \& Anderson 2002). A model set for each of the 10 algal genera was then constructed containing the linear or quadratic model for each exposure index as determined in the previous step. The null model was also included in the model set. The model containing the 'best' exposure index for our dataset was then determined using AIC, and the relative likelihood of each candidate model calculated using AIC weights (Burnham \& Anderson 2002). The percent deviance explained by the best model for each algal genus was also calculated and used a measure of goodness of fit.

Percent cover or abundance data gives a more complete description of biological patterns than occurrence data and therefore we also conducted GLMs on the percent cover of the same 10 algal genera examined in binomial tests. The broad functional groups canopy, understorey and encrusting algae were also included in percent cover analyses (Phillips et al. 1997). Data for each algal genera were arcsine-square root transformed (functional groups were left untransformed) and modelled with a Gaussian GLM with an identity link function. Although some data were still skewed after transformation, exploratory analyses with alternative GLM families indicated that Gaussian was the best option. The 'best' exposure index for explaining patterns in the cover of each algal genera or
Table 2. Spearman's rank correlations between exposure indices (see Table 1 for descriptions). Bold: highly correlated indices $(r>0.700)$

\begin{tabular}{|lllllll|}
\hline & Open & Wind & Bathy & Mean_Hs & 90_Hs & PWC \\
\hline Open & 1.000 & & & & & \\
Wind & $\mathbf{0 . 9 5 7}$ & 1.000 & & & & \\
Bathy & $\mathbf{0 . 7 1 6}$ & 0.647 & 1.000 & & & \\
Mean_Hs & 0.184 & 0.187 & 0.187 & 1.000 & & \\
90_Hs & 0.023 & 0.077 & 0.003 & $\mathbf{0 . 9 1 4}$ & 1.000 & \\
PWC & $\mathbf{0 . 9 1 1}$ & $\mathbf{0 . 9 0 7}$ & 0.668 & 0.255 & 0.083 & 1.000 \\
\hline
\end{tabular}

group was determined in the same manner as for occurrence data. All univariate tests were carried out in R 2.8.1 (R Development Core Team 2008).

\section{RESULTS}

\section{Properties of exposure indices}

The generated exposure indices were correlated to some degree (Table 2), with highly correlated indices $(r>0.7)$ being derived from similar sources. For example, openness was highly correlated with all indices that incorporated fetch $(\mathrm{r} \geq 0.716)$, but most correlated with wind fetch $(\mathrm{r}=0.957)$. Mean significant wave height derived from AusWAM was highly correlated with the 90th percentile of wave height derived from AusWAM ( $\mathrm{r}=0.914)$.

Despite the fact that many of the indices were correlated, each index emphasised a different component of exposure when summarised at a bioregional scale a) Open

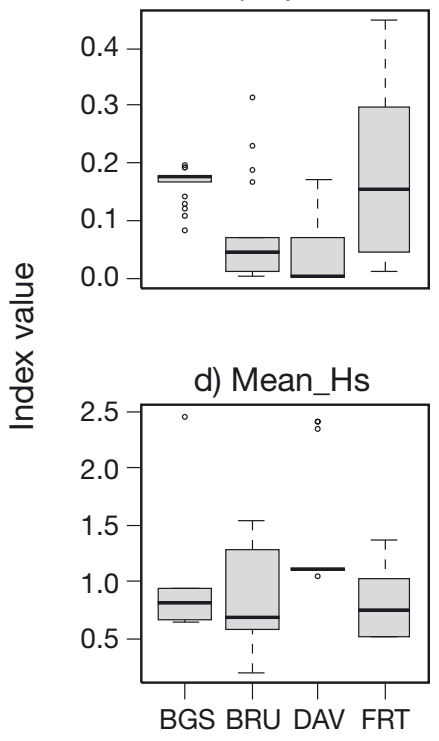

b) Wind

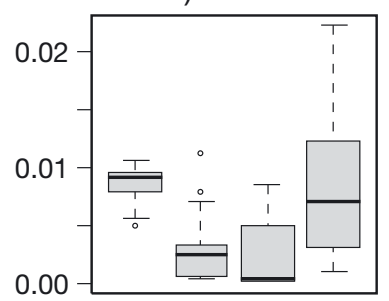

e) $90 \_\mathrm{Hs}$

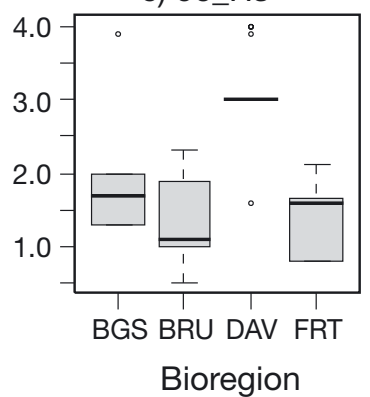

c) Bathy
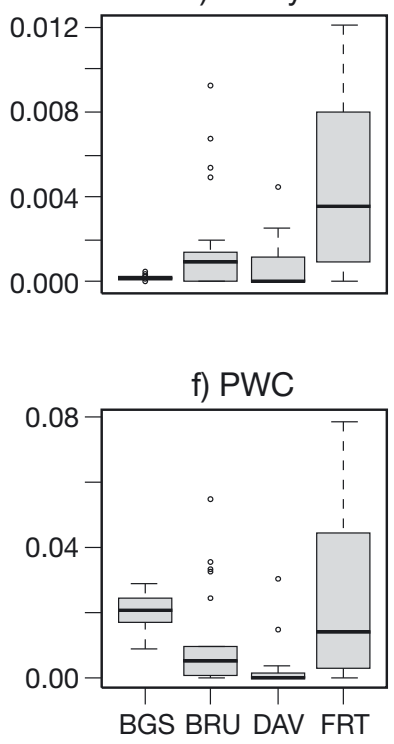

Fig. 2. Exposure indices by bioregion as boxplots. The horizontal line represents the median value of the exposure index, the top and bottom of the box represent the 25th and 75 th percentiles, respectively, and the whiskers are 2 standard deviations from the mean; points outside the whiskers represent outliers. Index descriptions are given in Table 1. Bioregions (see Fig. 1 for location): BGS = Boags; $\mathrm{BRU}=$ Bruny; DAV = Davey; FRT $=$ Freycinet 
(rather than site by site; see Fig. 2). Qualitatively, the openness and wind fetch indices assigned moderately high relative exposure values to sites in the Boags bioregion (adjacent to the Bass Strait; mean values 0.161 and 0.009 respectively) compared to sites on the southern coast (Bruny or Davey bioregions, i.e. 0.068 and 0.003 or 0.039 and 0.003 respectively; Fig. 2a,b). This reflects the fact that sites in the Boags region are located on an open coastline, and subject to strong winds across the Bass Strait, while sites in the southern bioregions are generally located in semi-enclosed areas. However, when the effect of bathymetry was included in fetch indices, measures of exposure were greatly reduced in the Boags bioregion, relative to the other bioregions (see Fig. 2c), due to the shallowness of the Bass Strait. Sites in the Freycinet bioregion encompass a mixture of open and semi-enclosed sites and consequently the exposure indices span a relatively large range (e.g. 0.02 to 0.48 for the openness index).

Broad-scale wave climate statistics, such as mean and 90th percentile of significant wave height, assigned relatively high average values (1.5 and 3.1, respectively) with little variation to sites in the Davey bioregion (Fig. 2d,e), an outcome in contrast to fetch measures. This is particularly emphasised in the 90th percentile_Hs (Fig. 2e) and corresponds to the susceptibility of this region to weather systems originating in the Southern Ocean. When the direction of mean significant wave height is combined with the openness, representing the potentially susceptibility of a site to the broad-scale wave climate, exposure values in the Davey bioregion are again down-weighted (Fig. 2f) due to the fact many sites occur in semi-enclosed areas (Fig. 1).

\section{Indices explaining patterns in community data}

All of the exposure indices significantly explained a proportion of variance in algal assemblage data. This indicates that quantitative exposure indices can effectively account for some of the patterns observed in the composition and relative abundance of algal assemblages on broad scales. The variance explained ranged from 10.4 to $17.8 \%$ (Table 3 ). The 4 indices that explained the greatest proportion of variation were openness $(17.8 \%)$, potential wave climate $(15.5 \%)$, wind fetch $(15.2 \%)$ and bathymetry-altered fetch (14.5\%).

\section{Indices explaining patterns in univariate data}

Exposure indices were able to explain up to $37.5 \%$ of the variance in the occurrence of individual algal genera (Table 4). However, none of the exposure indices
Table 3. Marginal significance and proportion of community-level variance explained by each exposure index (including its quadratic form), as calculated using DISTLM. In all cases; residual degrees of freedom $=76$, regression degrees of freedom $=3$. See Table 1 for descriptions of indices

\begin{tabular}{|lcccc|}
\hline Index & SS(trace) & Pseudo- $F$ & $p$ & $\begin{array}{c}\text { Proportion of } \\
\text { variance }\end{array}$ \\
\hline Open & 27849 & 8.216 & 0.0001 & 0.178 \\
Wind & 23766 & 6.797 & 0.0001 & 0.152 \\
Bathy & 22647 & 6.422 & 0.0001 & 0.145 \\
Mean_Hs & 16315 & 4.418 & 0.0001 & 0.104 \\
90_Hs & 18208 & 4.998 & 0.0001 & 0.116 \\
PWC & 24353 & 6.995 & 0.0001 & 0.155 \\
\hline
\end{tabular}

were a particularly good fit for Ecklonia $(6.0 \%$ deviance explained), perhaps because it is a ubiquitous alga in temperate regions. The most parsimonious models most often contained fetch-derived indices (Table 4; statistics for all models tested are in Table S1 of the supplement). Where fetch-based indices performed better, bathymetry-altered fetch was the best predictor in 5 out of 7 cases (Caulerpa, Durvillaea, Ecklonia, Lessonia, Phyllospora). Broad-scale wave climate indices were the best predictors only for Sargassum occurrence (in this case the 90th percentile of wave height index). The exposure index combining offshore wave climate and finer-scale fetch (potential wave climate) was the best predictor for the occurrence of 2 genera (Acrocarpia and Zonaria; Table 4). Models contained a mixture of linear and quadratic terms. In most cases, the best model from each candidate set for an alga was assigned a relative weight (wAIC) of $>0.8$, indicating that there was strong evidence that this was the best model in the candidate set (Table 4). The exception to this was Cystophora and Ecklonia where the relative weight of the best models was 0.439 and 0.312 respectively (Table 4).

Algal genera had distinct relationships with exposure. Genera such as Carpoglossum, Caulerpa, or Sargassum were more likely to be present when exposure was relatively low (i.e. $<1 / 3$ of the maximum value for the particular exposure index; Fig. 3b,c,i). In contrast, Durvillaea, and Phyllospora were less likely to occur when exposure was relatively low (Fig. 3e,h). Other genera such as Acrocarpia, Cystophora, Lessonia and Zonaria had a bell-shaped response to exposure and were more likely to occur at an intermediate value of relative exposure (Fig. 3a,d,g,j).

The exposure indices also explained a moderate proportion of variance in the percent cover data. The deviance explained by the most parsimonious model for each algal group ranged from 9.3 to $35.6 \%$ and was greatest for Acrocarpia (Table 4). However, the index identified as the best predictor of algal occurrence was 
Table 4. Model statistics for the index best predicting the occurrence and percent cover of each algal genera or group, as determined by Akaike's Information Criteria (AIC). Occurrence data were analysed using GLMs with binomial errors and a logit link function. Percent cover data were arcsine-square root transformed (excepting canopy, understorey and encrusting algae) and analysed using GLMs with a Gaussian error structure and identity link function. Columns: Model = terms included in the model; $\mathrm{k}=$ number of parameters estimated in the model $; \operatorname{LogL}=\log$-likelihood of the model $;$ wAIC $=$ AIC weight; $\%$ DE $=$ percent deviance explained by the model

\begin{tabular}{|c|c|c|c|c|c|c|c|c|c|c|}
\hline \multirow[b]{2}{*}{ Algae } & \multicolumn{5}{|c|}{ Presence/absence } & \multirow[b]{2}{*}{ Model } & \multicolumn{2}{|c|}{ ercent cover } & \multirow[b]{2}{*}{ wAIC } & \multirow[b]{2}{*}{$\% \mathrm{DE}$} \\
\hline & Model & $\mathrm{k}$ & $\log L$ & wAIC & $\% \mathrm{DE}$ & & $\mathrm{k}$ & $\log L$ & & \\
\hline Acrocarpia & $\mathrm{PWC}+\mathrm{PWC}^{2}$ & 3 & -33.75 & 0.969 & 37.49 & Open + Open $^{2}$ & 3 & 14.63 & 0.789 & 35.60 \\
\hline Carpoglossum & Open & 2 & -42.07 & 0.803 & 22.44 & Open + Open $^{2}$ & 3 & 51.45 & 0.834 & 34.30 \\
\hline Caulerpa & Bathy & 2 & -40.66 & 0.996 & 23.15 & Mean_Hs + Mean_Hs ${ }^{2}$ & 3 & 54.77 & 0.991 & 30.51 \\
\hline Cystophora & Open + Open ${ }^{2}$ & 3 & -43.01 & 0.439 & 15.22 & Open + Open $^{2}$ & 3 & 26.92 & 0.800 & 20.36 \\
\hline Durvillaea & Bathy & 2 & -32.86 & 0.796 & 28.17 & Bathy + Bathy ${ }^{2}$ & 3 & 0.65 & 0.549 & 18.56 \\
\hline Ecklonia & Bathy & 2 & -31.63 & 0.312 & 6.01 & Bathy + Bathy ${ }^{2}$ & 3 & 3.29 & 0.535 & 9.25 \\
\hline Lessonia & Bathy + Bathy ${ }^{2}$ & 3 & -30.70 & 1.000 & 31.31 & Bathy + Bathy ${ }^{2}$ & 3 & 76.31 & 0.991 & 20.47 \\
\hline Phyllospora & Bathy & 2 & -36.95 & 1.000 & 30.71 & Bathy + Bathy ${ }^{2}$ & 3 & -19.56 & 1.000 & 34.23 \\
\hline Sargassum & 90_Hs $+90 \_\mathrm{Hs}^{2}$ & 3 & -38.21 & 0.937 & 25.61 & 90_Hs + 90_Hs ${ }^{2}$ & 3 & 54.23 & 0.949 & 27.94 \\
\hline Zonaria & $\mathrm{PWC}+\mathrm{PWC}^{2}$ & 3 & -38.03 & 0.906 & 21.60 & Bathy & 2 & 59.83 & 0.698 & 16.15 \\
\hline Encrusting & Not tested & & & & & Mean_Hs & 2 & -356.50 & 0.706 & 16.22 \\
\hline Understorey & Not tested & & & & & Bathy & 2 & -340.91 & 0.999 & 28.79 \\
\hline Canopy & Not tested & & & & & Bathy + Bathy ${ }^{2}$ & 3 & -374.37 & 0.530 & 29.70 \\
\hline
\end{tabular}

a) Acrocarpia

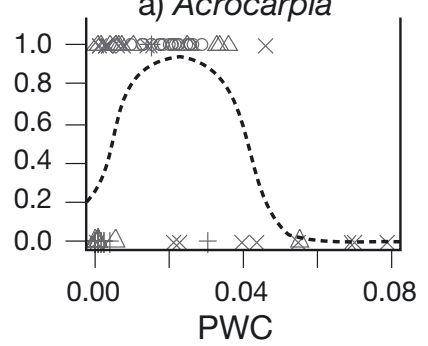

e) Durvillaea

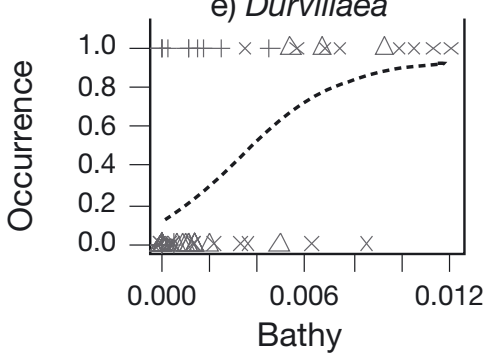

i) Sargassum

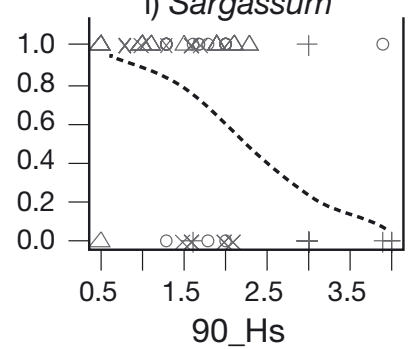

b) Carpoglossum

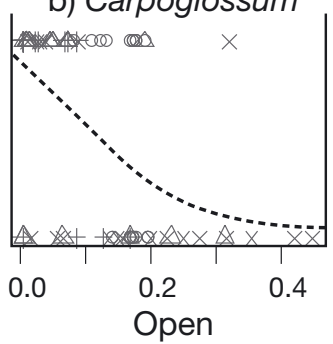

f) Ecklonia

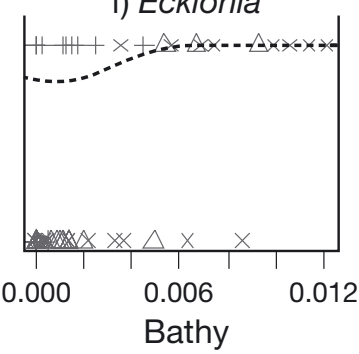

j) Zonaria

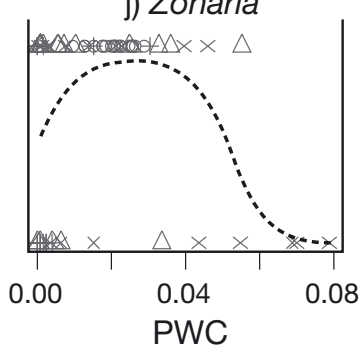

c) Caulerpa

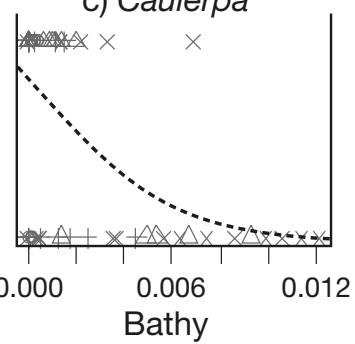

g) Lessonia

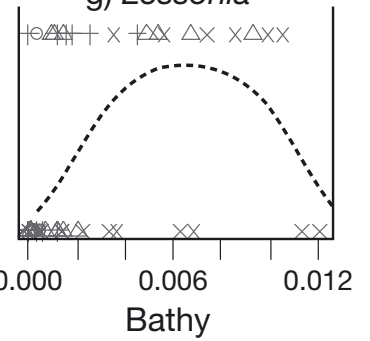

Index d) Cystophora

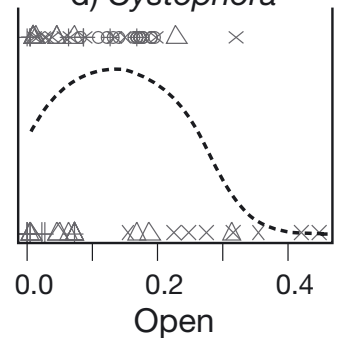

h) Phyllospora

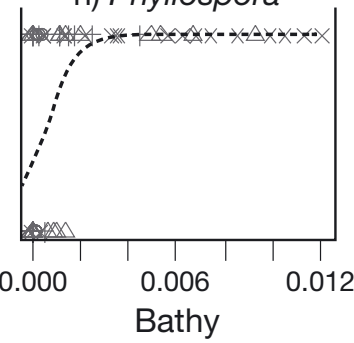

Bathy 012

Fig. 3. Best exposure index explaining the presence/ absence of 10 common algal genera in binomial GLMs. Index descriptions are given in Table 1. Grey symbols: data points; dashed line: fitted line from the best model. Data were back-transformed for plotting. Scale of the $\mathrm{x}$-axis differs between graphs. Bioregions: $\mathrm{O}=$ Boags; $\Delta=$ Bruny + = Davey; $X=$ Freycinet 

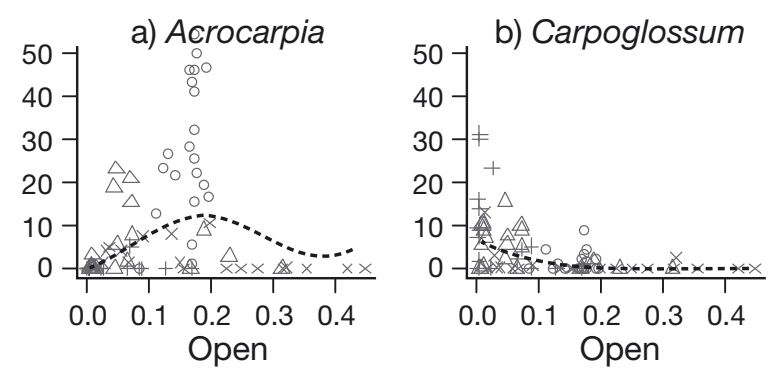

e) Durvillaea

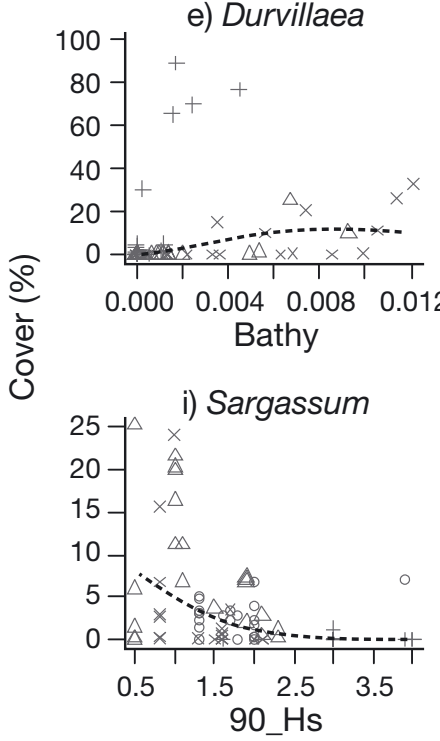

m) Canopy

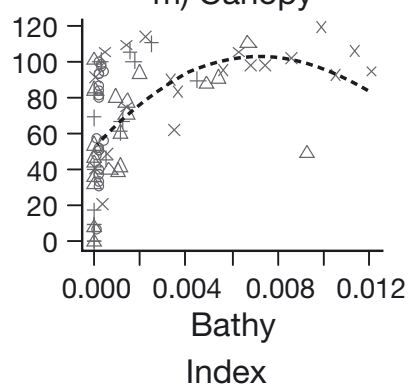

not always the best predictor for algal cover. For example, for Acrocarpia the best predictor of occurrence was potential wave climate, while openness was the best predictor of cover (Table 4). Again fetch-based indices performed well and were identified as the best predictors for 10 out of 13 of the algal groups, with bathymetry-altered fetch most often the best predictor of algal cover (Table 4). Indices derived from offshore wave climatology were the best predictors of Caulerpa, Sargassum, and encrusting algae (Table 4). However the combined index (potential wave climate) was not the best predictor for any algal group. The weight of evidence (wAIC) for the best model in each candidate set was generally high, but ranged from 0.530 to 0.949 (Table 4).
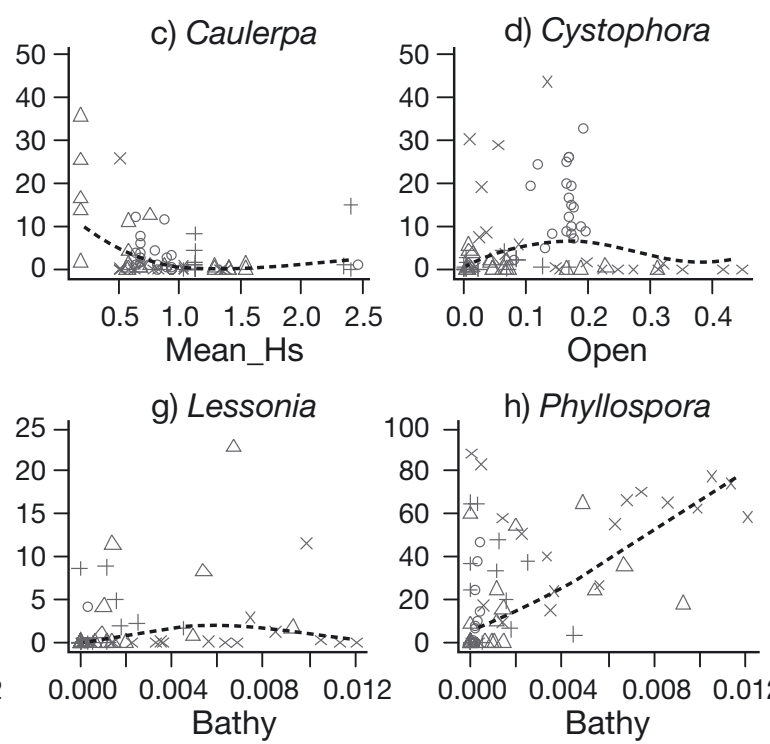

h) Phyllospora

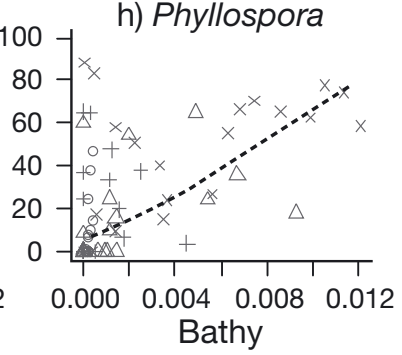

k) Encrusting
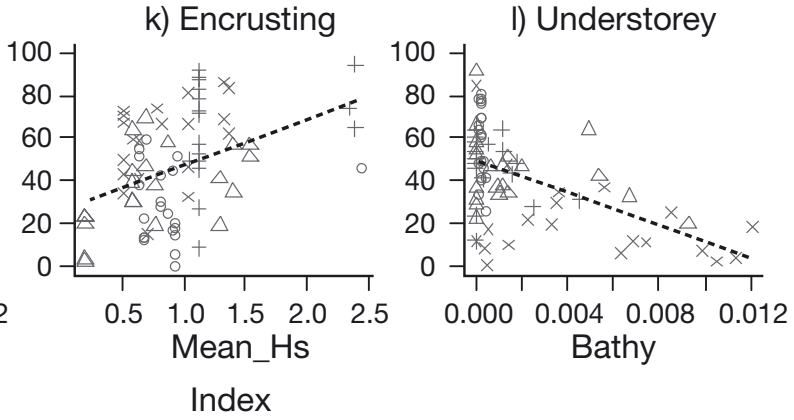

Index

Fig. 4. Best exposure index explaining the percent cover of 10 common algal genera and 3 broad groups in Gaussian GLMs. Index descriptions are given in Table 1. Grey symbols: data points; dashed lines: fitted line from the best model. Data were back-transformed for plotting. Scales on each graph are different. Bioregions: $O=$ Boags; $\Delta=$ Bruny;

$$
+=\text { Davey; } \times=\text { Freycinet }
$$

The relationships between the cover of algal genera and exposure followed a similar pattern to occurrence. The mean cover of Carpoglossum, Caulerpa, Sargassum and Zonaria decreased with increasing values of each alga's best exposure index (Fig. 4b,c,i,j). In contrast, mean Phyllospora cover increased with exposure to waves (Fig. 4h), and the remaining genera had greatest cover at intermediate exposure. When genera were aggregated to broad functional groups clear trends emerged. For example, the cover of encrusting algae was enhanced by increased exposure (Fig. 4k), while the cover of understorey algae decreased (Fig. 41). The cover of canopy forming algae was highest at intermediate exposure (values of $\sim 0.007$ for bathymetry-altered fetch; Fig. 4m). 


\section{DISCUSSION}

Using the outputs from offshore wave model hindcasts and cartographic fetch models, we were able to generate a suite of quantitative exposure indices for a series of shallow reef survey sites around the coast of Tasmania. The offshore model data used in this study were based on hindcasts compiled for other studies (Hemer 2006, Hughes \& Heap 2010). They had wide coverage (Australian coastal and continental shelf waters) and indices were relatively easy to obtain once the custodians of the datasets were identified and the requested model outputs were extracted. Similarly, we found that the minimum datasets needed for fetch modelling (i.e. a coastline and the location of sites) were easy to source and fetch indices were relatively simple to calculate within a GIS (using GREMO in this instance). However, calculating the wind fetch index required the pre-processing of meteorological records which was time consuming. The bathymetry-altered fetch also required additional information in the form of a bathymetry raster dataset for the entire area of interest. However, fetch modelling can also be conducted within a readily available GIS program and is quite flexible. Fetch-based indices can be generated for specific sites of interest (Ruuskanen et al. 1999, Bekkby et al. 2009), for entire coastlines, or on a customised grid (Kelly et al. 2001, Burrows et al. 2008).

In terms of predicting algal biodiversity, the performance of the different exposure indices can be summarised as follows. Indices derived from an offshore wave hindcast model were the best predictor of algal patterns in only a few instances. Although this model is accessible and available over a broad area, this likely indicates that offshore wave climate models are inappropriate for biodiversity modelling for a number of good reasons. Offshore wave models generally have too coarse a resolution compared to coastal biological data and they do not specifically model nearshore processes that result in fine-scale variability in wave exposure (Hughes \& Heap 2010). While the SWAN wave model (Simulating WAves Nearshore, Booij et al. 1999) specifically accounts for complex nearshore processes, it is only currently available for limited regions. Generating it for the Tasmanian region was beyond the scope of this study. In the absence of data from fine-scale shallow water wave models we suggest that cartographic fetch models provide good quantitative approximations of wave exposure for ecological modelling purposes. Fetchbased indices were in the majority of cases the best predictors for the occurrence and cover of algal genera and for community-level patterns. Of the 3 fetchbased indices generated in this study, the bathymetryaltered fetch was most often the best predictor of univariate algal patterns. However, because bathymetry-altered fetch also requires additional information that may be difficult to source, the simple openness measure is also useful.

The relationships between exposure and many of the algal genera in our study are consistent with observations and ecological expectations regarding the distribution of the Tasmanian marine flora (Edgar 1984). For example, our models show that the bull kelp, Durvillaea, is more likely to occur at exposed sites. Durvillaea is a large alga with a robust holdfast, thick stipe and thick blades. It is commonly found in southern temperate waters, and thrives in the shallow sub-tidal, generally on open, exposed coastlines where it forms dense beds and dominates community structure (Taylor \& Schiel 2010). Sargassum, a genus comprised of many species, is another common alga in Tasmanian and temperate waters. There is a range of morphologies within this genus, but most Sargassum species are not adapted to exposed environments and our models showed that both occurrence and abundance declined with increasing exposure. Sargassum undergoes large seasonal variations in morphology (Edgar 1983), dying back to a stipe in mid-summer (Collings \& Cheshire 1998). During winter (when exposure is maximal) it has large lateral branches that would increase drag and place strain on the relatively small holdfast. However, large laterals enhance nutrient uptake and are a competitive advantage in low exposure environments (Collings \& Cheshire 1998). Caulerpa, a relatively fragile green alga, was generally only present at any significant level of cover at sites with low exposure values.

The indices we generated were designed to emphasise different components of exposure. As a result, additional information on the probable mechanisms by which exposure influences the occurrence and abundance of particular genera can be derived. For example, the occurrence of Acrocarpia was best predicted by the combination of offshore wave climate and fetch (the potential wave climate index) while its cover was more influenced by the openness index. This suggests that the distribution of Acrocarpia, is influenced somewhat by oceanic conditions but that its cover is influenced by finer-scale, localised exposure. The ability to discriminate between different aspects of exposure provides the potential for developing testable hypotheses regarding the specific mechanisms driving the effect of exposure on a range of benthic community metrics.

This study has quantitatively re-affirmed the potential for exposure to be an effective surrogate for predicting biodiversity in shallow-reef ecosystems. In southern temperate Australia, fucoid algae often dominate reef assemblages and are important ecosystem 
engineers (Wernberg et al. 2003, Edgar et al. 2004, Goldberg \& Kendrick 2004). We have shown that exposure indices alone were able to predict up to $32 \%$ of the variation in occurrence and abundance of large fucoid species such as Phyllospora, Sargassum and Cystophora (Table 4) and up to $37 \%$ of any one algal genus (Acrocarpia). This is a promising result since there is a range of factors that will determine the occurrence and abundance of algal communities. These include other environmental variables such as temperature, nutrient concentrations (Kraufvelin et al. 2010) and light attenuation (Carruthers et al. 2002), that covary with exposure on a range of spatial scales. Biological interactions, such as herbivory (Ling 2008) and competition for space (Valentine \& Johnson 2003), and evolutionary constraints (Phillips 2001) are less easily quantified but also affect species' distributions. Preliminary work predicting shallow temperate reef biodiversity on broad spatial scales suggests that exposure is still an important predictor even when considered amongst a range of other measurable abiotic factors (N. A. Hill unpubl. data; Commonwealth of Australia's Environmental Research Facility Marine Biodiversity Hub). The ability of exposure indices to predict community patterns across several biogeographic regions confirms its potential value for future predictive modelling studies.

The fetch-based indices we calculated were effective for our purposes, but there is the potential for future work to extend the findings presented here. All indices calculated in this study quantify exposure to waves at the sea surface. No attempt was made to specifically account for water depth at a site. This model however, could easily incorporate depth following the work of Bekkby et al. (2008) if a sufficiently large depth range is present in the study area or the sites of interest.

While our study is focused on algal communities associated with shallow temperate reefs, exposure is an important force shaping a range of marine communities, and fetch-based indices should be equally applicable to ecological questions involving other assemblages in temperate and tropical waters (e.g. Fulton \& Bellwood 2004). Quantification of exposure across large areas will greatly improve predictive modelling of the distribution of shallow communities, which will address what is currently a fundamental challenge for improved coastal planning. Biodiversity modelling of communities using ecologically-meaningful, abiotic surrogates enables efficient use of field-sourced biological data. Newly-identified surrogates and better distribution models come at a critical time, when marine communities are under threat from a range of stresses, and improved management is vitally important for long-term conservation of inshore ecosystems.
Acknowledgements. This work has been funded through the Commonwealth Environment Research Facilities (CERF) program, an Australian Government initiative supporting world class, public-good research. The CERF Marine Biodiversity Hub is a collaborative partnership between the University of Tasmania, CSIRO Wealth from Oceans Flagship, Geoscience Australia, Australian Institute of Marine Science and Museum Victoria. We thank Richard Mount for access to computing facilities, Vanessa Lucieer for providing useful comments on the manuscript, Scott Foster and Russell Thomson for statistical advice and Justin Hulls for providing Fig. 2. The Generic Relative Exposure Model (GREMO) is a free and open source software (GNU-licensed) that has been developed to run in the ArcMap ${ }^{\mathrm{TM}}$ application. The source code will become available online in the near future.

\section{LITERATURE CITED}

Airoldi L, Cinelli F (1997) Effects of sedimentation on subtidal macroalgal assemblages: an experimental study from a mediterranean rocky shore. J Exp Mar Biol Ecol 215: 269-288

Anderson MJ, Gorley RN, Clarke KR (2008) PERMANOVA+ for PRIMER: Guide to software and statistical methods. PRIMER-E, Plymouth

Austin MP (1985) Continuum concept, ordination methods and niche theory. Annu Rev Ecol Syst 16:39-61

Austin MP (2002) Spatial prediction of species distribution: an interface between ecological theory and statistical modelling. Ecol Modell 157:101-118

Barrett NS, Buxton CD, Edgar GJ (2009) Changes in invertebrate and macroalgal populations in Tasmanian marine reserves in the decade following protection. J Exp Mar Biol Ecol 370:104-119

Beger M, Possingham HP (2008) Environmental factors that influence the distribution of coral reef fishes: modeling occurrence data for broad-scale conservation and management. Mar Ecol Prog Ser 361:1-13

> Bekkby T, Isachsen PE, Isaeus M, Bakkestuen V (2008) GIS modeling of wave exposure at the seabed: a depthattenuated wave exposure model. Mar Geod 31:117-127

Bekkby T, Rinde E, Erikstad L, Bakkestuen V (2009) Spatial predictive distribution modelling of the kelp species Laminaria hyperborea. ICES J Mar Sci 66:2106-2115

> Bolton JJ (1994) Global seaweed diversity: patterns and anomalies. Bot Mar 37:241-245

Booij N, Ris RC, Holthuijsen LH (1999) A third-generation wave model for coastal regions I. Model description and validation. J Geophys Res, C, Oceans 104:7649-7666

Burnham KP, Anderson DR (2002) Model selection and multimodel inference: a practical information-thoeretic approach, 2nd edn. Springer, New York, NY

Burrows MT, Harvey R, Robb L (2008) Wave exposure indices from digital coastlines and the prediction of rocky shore community structure. Mar Ecol Prog Ser 353:1-12

Carruthers TJB, Dennison WC, Longstaff BJ, Waycott M, Abal EG, McKenzie LJ, Lee Long WJL (2002) Seagrass habitats of north-east Australia: models of key processes and controls. Bull Mar Sci 71:1153-1169

Collings GJ, Cheshire AC (1998) Composition of subtidal macroalgal communities of the lower gulf waters of South Australia, with reference to water movement and geographic separation. Aust J Bot 46:657-669

Commonwealth of Australia (2006) A guide to the integrated marine and coastal regionalisation of Australia, Version 4.0. Department of the Environment and Heritage, Canberra 
Condie SA, Dunn JR (2006) Seasonal characteristics of the surface mixed layer in the Australasian region: implications for primary production regimes and biogeography. Mar Freshw Res 57:569-590

> D'Amours O, Scheibling RE (2007) Effect of wave exposure on morphology, attachment strength and survival of the invasive green alga Codium fragile ssp. tomentosoides. J Exp Mar Biol Ecol 351:129-142

Denny MW (1988) Biology and the mechanics of the waveswept environment. Princeton University Press, Princeton, NJ

- Edgar GJ (1983) The ecology of south-east Tasmanian phytal animal communities. II. Seasonal change in plant and animal populations. J Exp Mar Biol Ecol 70:159-179

Edgar GJ (1984) General features of the ecology and biogeography of Tasmanian subtidal rocky shore communities. Papers \& Proceedings - Royal Society of Tasmania 118: 173-186

Edgar GJ, Barrett NS, Morton AJ, Samson CR (2004) Effects of algal canopy clearance on plant, fish and macroinvertebrate communities on eastern Tasmanian reefs. J Exp Mar Biol Ecol 312:67-87

> Ekebom J, Laihonen P, Suominen T (2003) A GIS-based stepwise procedure for assessing physical exposure in fragmented archipelagos. Estuar Coast Shelf Sci 57:887-898

England PR, Phillips J, Waring JR, Symonds G, Babcock R (2008) Modelling wave-induced disturbance in highly biodiverse marine macroalgal communities: support for the intermediate disturbance hypothesis. Mar Freshw Res 59: 515-520

Fonseca MS, Bell SS (1998) Influence of physical setting on seagrass landscapes near Beaufort, North Carolina, USA. Mar Ecol Prog Ser 171:109-121

Foster SD, Dunstan PK (2010) The analysis of biodiversity using rank abundance distributions. Biometrics 66: 186-195

- Fowler-Walker MJ, Connell SD, Gillanders BM (2005) To what extent do geographic and associated environmental variables correlate with kelp morphology across temperate Australia? Mar Freshw Res 56:877-887

> Fulton CJ, Bellwood DR (2004) Wave exposure, swimming performance, and the structure of tropical and temperate reef fish assemblages. Mar Biol 144:429-437

Goldberg NA, Kendrick GA (2004) Effects of island groups, depth, and exposure to ocean waves on subtidal macroalgal assemblages in the Recherche Archipelago, Western Australia. J Phycol 40:631-641

Greensdale DJM (2001) The assimilation of ERS-2 significant wave height data in the Australian region. J Mar Syst 28: $141-451$

Guisan A, Lehmann A, Ferrier S, Austin M, Overton JM, Aspinal R, Hastie T (2006) Making better biogeographical predictions of species' distributions. J Appl Ecol 43: 386-392

- Hemer MA (2006) The magnitude and frequency of combined flow bed shear stress as a measure of exposure on the Australian continental shelf. Cont Shelf Res 26:1258-1280

Hemer MA, McInnes K, Church JA, O'Grady J, Hunter JR (2008) Variability and trends in the Australian wave climate and consequent coastal vulnerability. The Centre for Australian Weather and Climate Research, Hobart

> Hoegh-Guldberg O, Mumby PJ, Hooten AJ, Steneck RS and others (2007) Coral reefs under rapid climate change and ocean acidification. Science 318:1737-1742

Hughes MG, Heap AD (2010) National-scale wave energy resource assessment for Australia. Renew Energy 35: 1783-1791
Hunt HL, Scheibling RE (1996) Physical and biological factors influencing mussel (Mytilus trossulus, M. edulis) settlement on a wave-exposed rocky shore. Mar Ecol Prog Ser 142:135-145

Hurd CL (2000) Water motion, marine macroalgal physiology, and production. J Phycol 36:453-472

Jackson JBC, Kirby MX, Berger WH, Bjorndal KA and others (2001) Historical overfishing and the recent collapse of coastal ecosystems. Science 293:629-638

Johnston EL, Roberts DA (2009) Contaminants reduce the richness and evenness of marine communities: a review and meta-analysis. Environ Pollut 157:1745-1752

Kelly NM, Fonseca M, Whitfield P (2001) Predictive mapping for management and conservation of seagrass beds in North Carolina. Aquat Conserv: Mar Freshw Ecosyst 11: 437-451

Kennelly SJ (1989) Effects of kelp canopies on understorey species due to shade and scour. Mar Ecol Prog Ser 50: 215-224

> Kraufvelin P, Lindholm A, Foldager Pedersen M, Andreas Kirkerud L, Bonsdorff E (2010) Biomass, diversity and production of rocky shore macroalgae at two nutrient enrichment and wave action levels. Mar Biol 157:29-47

Lehmann A, Leathwick JR, Overton JM (2002) Assessing New Zealand fern diversity from spatial predictions of species assemblages. Biodivers Conserv 11:2217-2238

> Lindegarth M, Gamfeldt L (2005) Comparing categorical and continuous ecological analyses: Effects of 'wave exposure' on rocky shores. Ecology 86:1346-1357

> Ling SD (2008) Range expansion of a habitat-modifying species leads to loss of taxonomic diversity: a new and impoverished reef state. Oecologia 156:883-894

Malhotra A, Fonseca MS (2007) WEMo (Wave Exposure Model): formulation, procedures and validation, National Oceanic and Atmospheric Administration, Beaufort, NC

> McArdle BH, Anderson MJ (2001) Fitting multivariate models to community data: a comment on distance-based redundancy analysis. Ecology 82:290-297

Pepper A (2009) Extension, generalisation, and verification of a GIS-based relative wave exposure model. BSc Hons dissertation, University of Wollongong, NSW

Pepper A, Puotinen ML (2009) GREMO: A GIS-based generic model for estimating relative wave exposure. In: Anderssen RS, Braddock RD, Newham LTH (eds) 18th World IMACS Congress and MODSIM09 International Congress on Modelling and Simulation. Modelling and Simulation Society of Australia and New Zealand and International Association for Mathematics and Computers in Simulation, Cairns, p 1964-1970

Phillips J (2001) Marine macroalgal biodiversity hotspots: Why is there high species richness and endemism in southern Australian marine benthic flora? Biodivers Conserv 10: 1555-1577

> Phillips JC, Kendrick GA, Lavery PS (1997) A test of a functional group approach to detecting shifts in macroalgal communities along a disturbance gradient. Mar Ecol Prog Ser 153:125-138

Porter-Smith R, Harris PT, Anderson OB, Coleman R, Greenslade DJM, Jenkins CJ (2004) Classification of the Australian continental shelf based on predicted sediment threshold exceedance from tidal currents and swell waves. Mar Geol 211:1-20

Puotinen ML (2005) An automated GIS method for modelling relative wave exposure within complex reef-island systems. A case study of the Great Barrier Reef. In: Zerger A, Argent RM (eds) MODSIM: Int Congr Modelling and Simulation, Dec 2005. Modelling and Simulation Society of 
Australia and New Zealand, p 170-176

R Development Core Team (2008) R: A language and environment for statistical computing. R Foundation for Statistical Computing, Vienna

Reid WV (1998) Biodiversity hotspots. Trends Ecol Evol 13: $275-280$

Ruuskanen A, Bäck S, Reitalu T (1999) A comparison of two cartographic exposure methods using Fucus vesiculosus as an indicator. Mar Biol 134:139-145

Stuart-Smith RD, Barrett NS, Stevenson DG, Edgar GJ (2010) Stability in temperate reef communities over a decadal time scale despite concurrent ocean warming. Glob Change Biol 16:122-134

Taylor DI, Schiel DR (2010) Algal populations controlled by fish herbivory across a wave exposure gradient on southern temperate shores. Ecology 91:201-211

Thomson MS, Wernberg T, Kendrick GA (2004) The effect of thallus size, life stage, aggregation, wave exposure and substratum condition on the forces required to break or dislodge the small kelp Ecklonia radiata. Bot Mar 47: 545-560

Vadas RL, Wright WA, Mille SL (1990) Recruitment of Ascophylllum nodosum: wave action as a source of mortality. Mar Ecol Prog Ser 61:263-272

> Valentine JP, Johnson CR (2003) Establishment of the intro-

Editorial responsibility: Brian Helmuth, Columbia, South Carolina, USA duced kelp Undaria pinnatifida in Tasmania depends on disturbance to native algal assemblages. J Exp Mar Biol Ecol 295:63-90

> Walker DI (1998) Threats to macroalgal diversity: marine habitat destruction and fragmentation, pollution and introduced species. Bot Mar 41:105-112

WAMDI Group (1988) The WAM Model: a third generation ocean wave prediction model. J Phys Oceanogr 18: $1775-1810$

Wernberg T, Thomsen MS (2005) The effect of wave exposure on the morphology of Ecklonia radiata. Aquat Bot 83:61-70

> Wernberg T, Kendrick GA, Phillips J (2003) Regional differences in kelp-associated algal assemblages on temperate limestone reefs in south-western Australia. Divers Distrib 9:427-441

Whiteway TG (2009) Australian bathymetry and topography grid, Geoscience Australia, Canberra

Williams JN, Seo C, Thorne J, Nelson JK, Erwin S, O'Brien JM, Schwartz MW (2009) Using species distribution models to predict new occurrences for rare plants. Divers Distrib 15:565-576

Zibordi G (2009) Validation of satellite ocean color primary products at optically complex coastal sites: northern Adriatic Sea, northern Baltic Proper and Gulf of Finland. Remote Sens Environ 113:2574-2591

Submitted: May 14, 2010; Accepted: September 8, 2010 Proofs received from author(s): October 29, 2010 